\title{
ANÁLISIS BIOANTROPOLÓGICO DE UN ENTERRATORIO HUMANO DEL HOLOCENO TARDÍO EN CABO NOSE, TIERRA DEL FUEGO, CHILE
}

\author{
MARTA P. ALFONSO-DURRUTY*, ELISA CALÁS'** Y FLAVIA MORELLO***
}

\begin{abstract}
RESUMEN
Se presenta el hallazgo fortuito, excavación y análisis de un enterratorio humano en Cabo Nose, Tierra del Fuego, Chile. El enterratorio se encontraba depositado en un conchal compuesto principalmente de choritos y mauchos, así como de algunos huesos de pescados, aves y mamíferos (lobo marino y guanaco). Los restos esqueletales correspondían a un individuo adulto joven de sexo masculino, fechado en 980 +/-40 años AP (Holoceno tardío). El esqueleto presenta hiperostosis porótica y espina bífida oculta, que posiblemente fueron consecuencia de una dieta rica en alimentos de origen animal pero pobre en vegetales y por tanto en folatos. Esta carencia nutritiva habría afectado al individuo durante el periodo gestacional (espina bífida oculta) y durante la niñez (hiperostosis porótica). Sin embargo, es también posible que un defecto genético haya causado los problemas congénitos (espina bífida y coaliciones tarsales) identificados en este individuo. El análisis isotópico indica un claro predominio de dieta marítima, lo cual concuerda con la evidencia paleopatológica.
\end{abstract}

PALABRAS CLAVE: restos humanos, Tierra del Fuego, Holoceno tardío, espina bífida oculta, hiperostosis porotica.

\section{BIOANTHROPOLOGICAL ANALYSIS OF A LATE HOLOCENE HUMAN BURIAL FROM CABO NOSE, TIERRA DEL FUEGO, CHILE}

\footnotetext{
ABSTRACT

The discovery, excavation and analysis of a burial in Cabo Nose, Tierra del Fuego, Chile, is presented. The burial was deposited in a shell midden composed mostly of mussels and Nacella sp., as well as some fish, birds and mammal bones (sea lion and guanaco). The remains corresponded to a young adult male dated to BP 980+/-40 (Late Holocene). The skeleton showed porotic hyperostosis, spina bifida occulta, and deformities in the tarsal bones of the left foot. These anomalies were most likely the

* Department of Anthropology, University Museum, y Reproductive Ecology Laboratory, University of Pennsylvania. 3260 South Street, Philadelphia PA 19104, USA. madurruty@yahoo.com.

* Arqueóloga, Universidad de Chile. Juan Moya 910 (Ñuñoa), Santiago, Chile. elisa.calas@gmail.com

** Universidad de Magallanes, Instituto de la Patagonia, Centro de Estudios del Hombre Austral. Av. Bulnes 01890, Punta Arenas, Chile. flavia.morello@umag.cl.
} 
result of a folate dietary deficiency caused by the ingestion of a diet that was rich in meats, but poor in leafy-green vegetables. This dietary deficiency affected the individual during the gestational period (spina bifida occulta) and childhood (porotic hyperostosis). It is also possible, however, that the congenital defects seen in this individual (spina bifida occulta and tarsal coalitions), were the result of a genetic condition. The isotopic analysis shows that this individual consumed a diet that was predominantly maritime, which is in agreement with the paleopathological evidence.

KEY WORDS: human remains, Tierra del Fuego, late Holocene, spina bifida occulta, porotic hyperostosis.

\section{INTRODUCCIÓN}

El hallazgo fortuito de restos humanos prehistóricos en las costas de Fuego-Patagonia es un hecho común que ha sido tratado desde diversas perspectivas, incluyendo la existencia de factores formacionales que actúan a una escala regional, como la tendencia a depositar restos humanos en lugares donde se han desarrollado actividades nofunerarias de tipo doméstico (Guichón et al. 2001). También se ha planteado la existencia de un modo tafonómico asociado a ámbitos marinos costeros y la existencia de preservación diferencial positiva en los sectores litorales (Martin 2006). La presente nota aborda el salvataje arqueológico de los restos óseos humanos detectados en cabo Nose, Tierra del Fuego. Este enterratorio constituye un caso más de este tipo de registro para la isla grande de Tierra del Fuego.

El enterratorio humano de Cabo Nose fue descubierto por lugareños que dieron aviso a la Policía de Investigaciones de Chile (PDI), quienes iniciaron un caso judicial. La policía recolectó los elementos óseos que se encontraban dispersos y

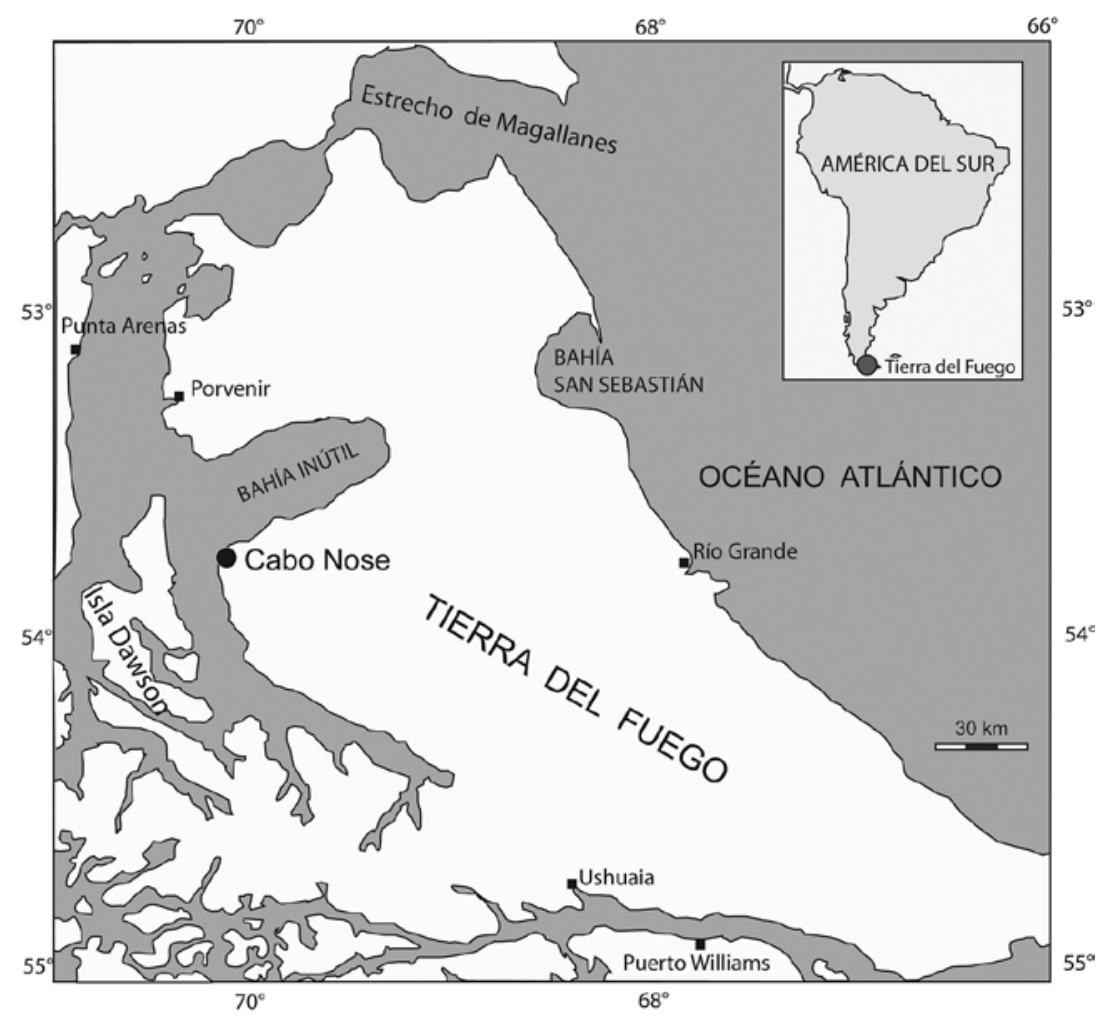

Fig. 1. Ubicación del sitio del hallazgo en Cabo Nose, Tierra del Fuego. 
desarticulados. El resto del esqueleto, que se encontraba semienterrado, fue dejado in situ. Ante la sospecha de que se trataba de restos indígenas de antigua data, la fiscalía y los detectives investigadores solicitaron colaboración arqueológica al Centro de Estudios del Hombre Austral (CEHA) del Instituto de la Patagonia, Universidad de Magallanes. Una vez confirmado el carácter arqueológico del hallazgo, se decidió planificar el salvataje de los restos dejados in situ en octubre del 2008.

\section{Hallazgo y Salvataje}

El sitio del enterratorio se ubica en el extremo sur-oeste de bahía Inútil, adyacente a la playa, en el sector de cabo Nose. Las mareas erosionaron la terraza marina actual y el perfil del conchal donde se encontraban depositados los restos humanos, a menos de un metro sobre el nivel del mar actual (Fig. 1 y 2). El sedimento removido por la erosión del mar y la acción antrópica (PDI) presentaba numerosas espículas de carbón, restos de fauna (guanaco, ave, peces y un posible pinnípedo) e instrumentos líticos (raspador, raedera, lascas y piedras con pigmentos). Las labores de harneo de este sedimento permitieron recuperar más elementos óseos humanos.

Considerando la posición del esqueleto, se excavó una unidad de rescate hacia el interior de la terraza marina de $77 \times 50 \mathrm{~cm}$, ya que se preveía el salvataje de las extremidades inferiores del individuo. Las partes del esqueleto que se encontraban expuestas y articuladas correspondían a algunas costillas, vértebras toráxicas, pelvis y un fragmento de la epífisis proximal de fémur.

El sector excavado se hallaba cubierto de pasto. Los primeros niveles artificiales de la excavación (0-30 $\mathrm{cm}$ profundidad, matriz de arena gris) no contenían material cultural. El estrato arqueológico, un conchal compuesto principalmente de choritos y mauchos, así como de algunas lapas y caracoles (trophon, y piquilhue), comenzaba a presentarse a los $37 \mathrm{~cm}$ de profundidad y contenía abundantes restos de carbón. En este estrato se registran huesos de fauna, entre ellos considerables restos de pescado y aves, algunos elementos de lobo marino y posiblemente fragmentos de guanaco. El sedimento incluía material lítico (5 lascas) y dos piedras grandes, que cubrían las extremidades inferiores del individuo (Fig. 3). La extremidad inferior derecha y ambos pies estaban

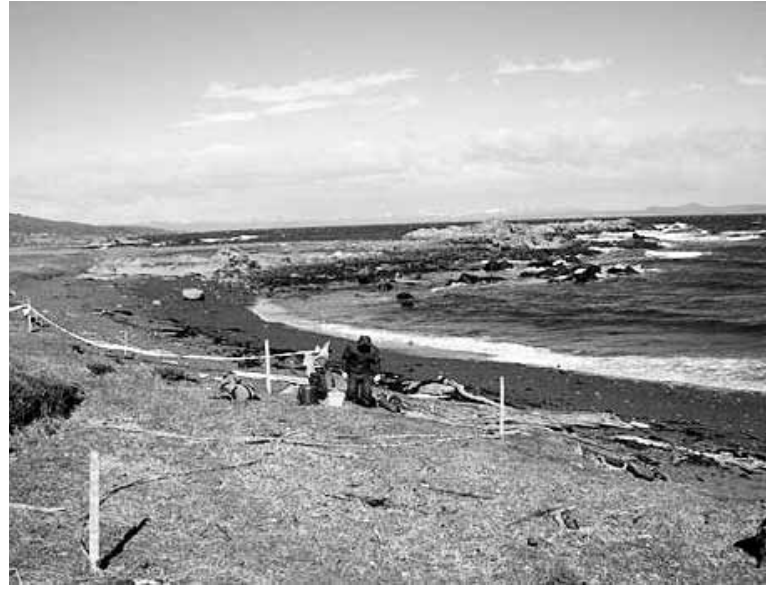

Fig. 2. Vista general del sector del hallazgo de osamentas humanas.

desarticulados. Al terminar la excavación se nota que el esqueleto descansa sobre una delgadísima capa de conchal, casi apoyado en la playa actual. No fue posible hallar el brazo derecho, ni las clavículas.

El individuo se encontraba depositado de cúbito dorsal y en posición semi-flectada, y fue identificado con el número de inventario $\mathrm{N}^{\circ} 89014$ del CEHA.

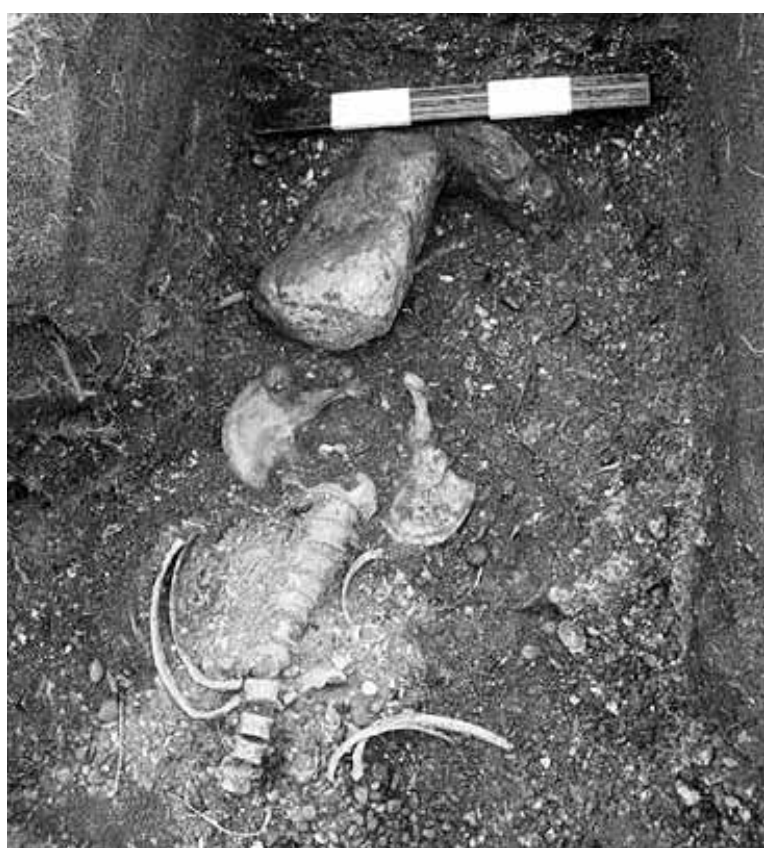

Fig. 3. Vista general del torso superior del entierro y las piedras cubriendo las extremidades inferiores del individuo. 
Tabla 1. Determinación de la Edad.

\begin{tabular}{|c|c|c|}
\hline \multirow[t]{2}{*}{ Rasgo } & \multicolumn{2}{|c|}{ Edad en años } \\
\hline & Derecho & Izquierdo \\
\hline Suturas Craneanas $^{1}$ & & \\
\hline Sínfisis Púbica & $22-24^{2} / 18-34^{3}$ & $25-26^{2} / 18-34^{3}$ \\
\hline Superficie Auricular ${ }^{4}$ & $20-24$ & $20-24$ \\
\hline Vértebras Sacras ${ }^{5}$ & \multicolumn{2}{|c|}{25} \\
\hline
\end{tabular}

${ }^{1}$ Meindl y Lovejoy (1985); ${ }^{2}$ Todd (1921); ${ }^{3}$ Brooks y Suchey (1990); ${ }^{4}$ Lovejoy et al. (1985); Meindl y Lovejoy (1989); ${ }^{5}$ Buikstra y Ubelaker (1994).

\section{INDIVIDUO Nº 89014}

Los restos del individuo $\mathrm{N}^{\circ} 89014$ fueron analizados siguiendo los procedimientos internacionales estándar (Buikstra y Ubelaker 1994). El análisis estadístico se efectuó en SPSS 17. El esqueleto presentaba evidencia de disturbación post-mortem, aunque se encuentra relativamente completo y en buen estado de conservación. Los restos presentan marcas de raíces, pocas fracturas post-mortem y un caso con huellas de la actividad de un cánido de pequeño tamaño. Este último corresponde a marcas de punctures, pits y furrow (sensu Binford 1981) en el área dorsal de la tercera costilla derecha. La porción antero-lateral derecha del cráneo estuvo expuesta a condiciones subaéreas, que se evidencian en la coloración blanquecina y el aspecto meteorizado del hueso.

Dada la ubicación del entierro, es posible que la erosión marina y la pendiente de la terraza hayan socavado la playa bajo el entierro, lo que produjo su hundimiento y exposición. La desarticulación y pérdida de algunos elementos óseos se debería a estos procesos geológicos y la posible acción de cánidos.

El análisis de la pelvis y el cráneo indican que los restos óseos encontrados en cabo Nose corresponden a un individuo adulto joven (20-35 años; Tabla 1) de sexo masculino (Tabla 2), cuya estatura era de entre 153,50-172,24 cm (Tabla 3). El índice craneano $(70,97)$ cae en el rango de dolicocefálico $e$ indica que el cráneo es largo y angosto.

Todas las piezas dentales maxilares se encuentran presentes. En las piezas inferiores se observan cuatro pérdidas post-mortem (I1 izquierdo, I2 derecho, Pm2 derecho y M1 derecho). El exámen dental reveló la ausencia de fracturas, caries y abscesos. Tres piezas maxilares derechas (M1, P1 y C) y una pieza del hemi-maxilar izquierdo (C) presentan chipping. Este tipo de pérdida del esmalte se debe a la presencia de partículas duras en la dieta (e.g. arenas y conchas). El 94,1\% las piezas anteriores y premolares presenta un grado de abrasión moderado (grados 4-5; Smith, 1984). En los molares la abrasión varía de leve a moderada (grados 6-19), con el $81,8 \%$ de las piezas desgastadas entre los grados 6 y 16 (Scott, 1979). La mayoría de las piezas dentales presentan tártaro (46,4\%; Fig. 4) en $1 / 3$ de su corona y sólo el 3,6\% presenta depositaciones que cubren más del 75\% de la corona (Brothwell 1981). La reabsorción alveolar es moderada ( $\mu=2,7$; $\mathrm{ds}=0,67$ ) y posiblemente se desarrolló a consecuencia del desgaste dental. Ocho piezas dentales presentan líneas hipoplásticas horizontales de color blanco/ crema (Fig. 4c). El análisis de las hipoplasias dentales indica que éstas se formaron a la edad de 3-6 años ( $\mu=4.8, s d=.98$; Goodman y Rose 1990). La

Tabla 2. Determinación del Sexo.

\begin{tabular}{|ll|ll|}
\hline \multicolumn{2}{|c|}{ PELVIS } & & \multicolumn{2}{c|}{ CRÁNEO } \\
Rasgo & Sexo (D/I) & Rasgo & Sexo (D/I) ${ }^{1}$ \\
\hline Arco Ventral & Masculino/Masculino & Cresta Nucal & Masculino/Masculino \\
Concavidad Subpúbica & Masculino/Masculino & Proceso Mastoideo & Masculino/Masculino \\
Puente Rama Isquio-Púbica & Masculino/Masculino & Margen Supraorbital & Masculino/Masculino \\
Escotadura Ciática & Masculino/Masculino & Glabela & Masculino/Masculino \\
Surco Pre-auricular & Masculino/Masculino & Eminencia Mentoniana & Mado \\
\hline
\end{tabular}

${ }^{1}$ D/I: Derecho/Izquierdo. 
Tabla 3. Determinación de la estatura.

\begin{tabular}{|l|llllll|}
\hline & Medida $(\mathrm{mm})$ & Mongoloide $^{1}$ & \multicolumn{3}{c}{ Mexicano $^{1}$} & Mesoamericano $^{2}$ \\
\hline & & Media & Rango & Media & Rango & 155.4 \\
Húmero & 28.7 & 160.106 & $155.95-164.27$ & 157.74 & $153.5-161.98$ & 162.2 \\
Radio & 24 & 166.96 & $162.36-171.56$ & 165.91 & $161.87-169.91$ & 16.1 \\
Ulna & 25.9 & 167.6 & $162.92-172.2$ & 166.8 & $162.7-170.1$ & 162.8 \\
Fémur & 40.5 & 159.6 & $155.85-163.5$ & 157.5 & $154.5-163.5$ & 155.5 \\
Tibia & 34.8 & 164.6 & $161.35-167.9$ & 162.3 & $158.6-166.1$ & 159.4 \\
\hline
\end{tabular}

${ }^{1}$ Trotter y Glesser 1952, 1958; ${ }^{2}$ del Angel y Cisneros 2004.

estimación de la edad al momento de la formación de estos defectos hipoplásticos debe ser considerada con precaución ya que cálculos basados en medidas histológicas podrían indicar formaciones a edades más avanzadas (Ritzman et al. 2008). Los dientes del individuo $\mathrm{N}^{\circ} 89014$ no presentan evidencia de modificación o uso parafuncional.
Tanto el frontal como los parietales presentan depositaciones óseas con poros pequeños y bordes escleróticos reabsorbidos. Estas lesiones corresponden a una hiperostosis porótica que se encontraba inactiva (sanada) al momento de la muerte (Fig. 4). El húmero izquierdo presenta pérdida ósea localizada en la fosa radial y dos áreas del surco intertubercular.
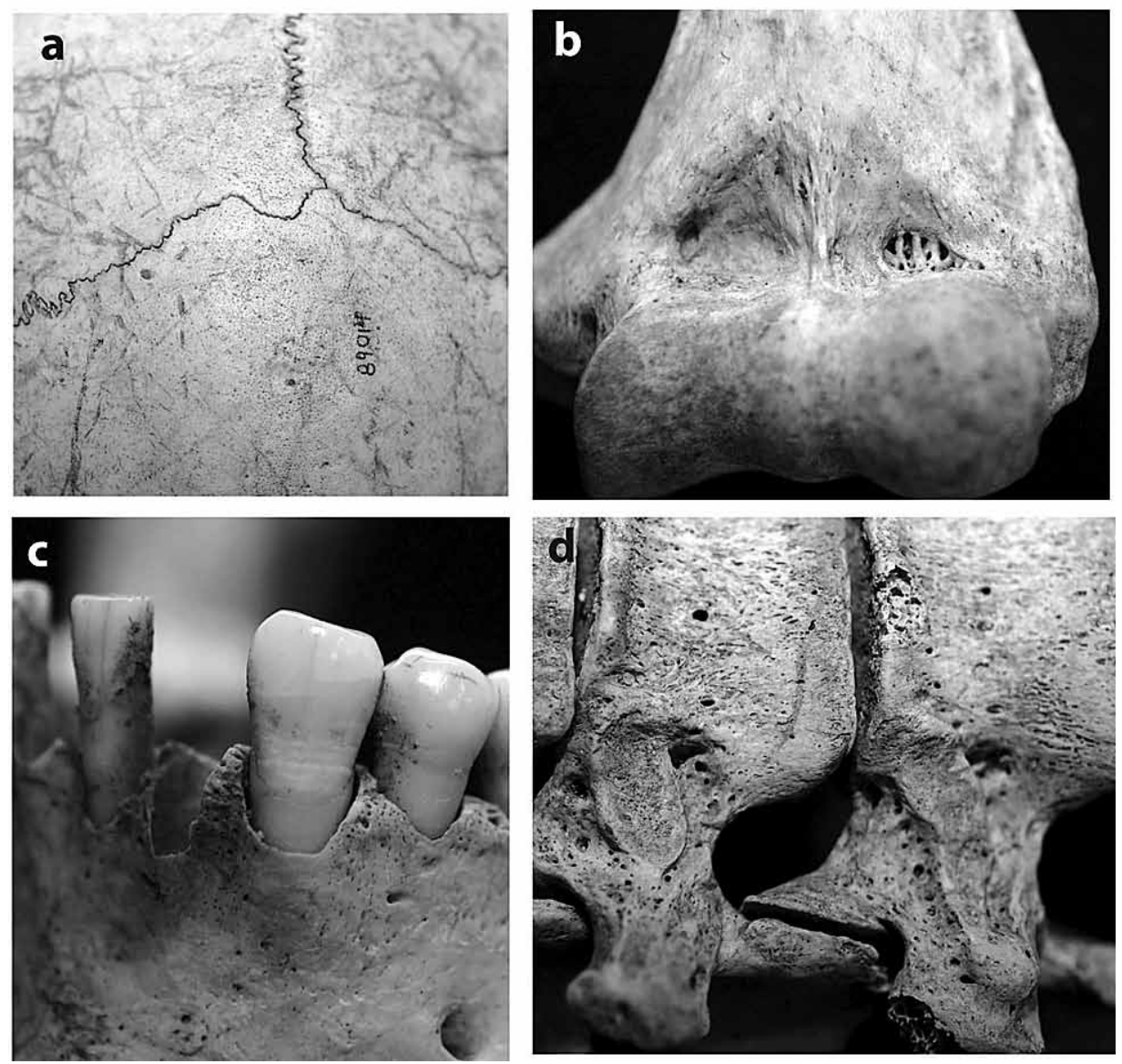

Fig. 4. a) Hiperostosis porótica en el frontal y parietales; b) Fosa Radial con destrucción localizada del hueso cortical; c) Hipoplasia del esmalte y tártaro en el canino inferior izquierdo; d) Vértebras torácicas (T9 y T10) con facetas articulares elongadas. 

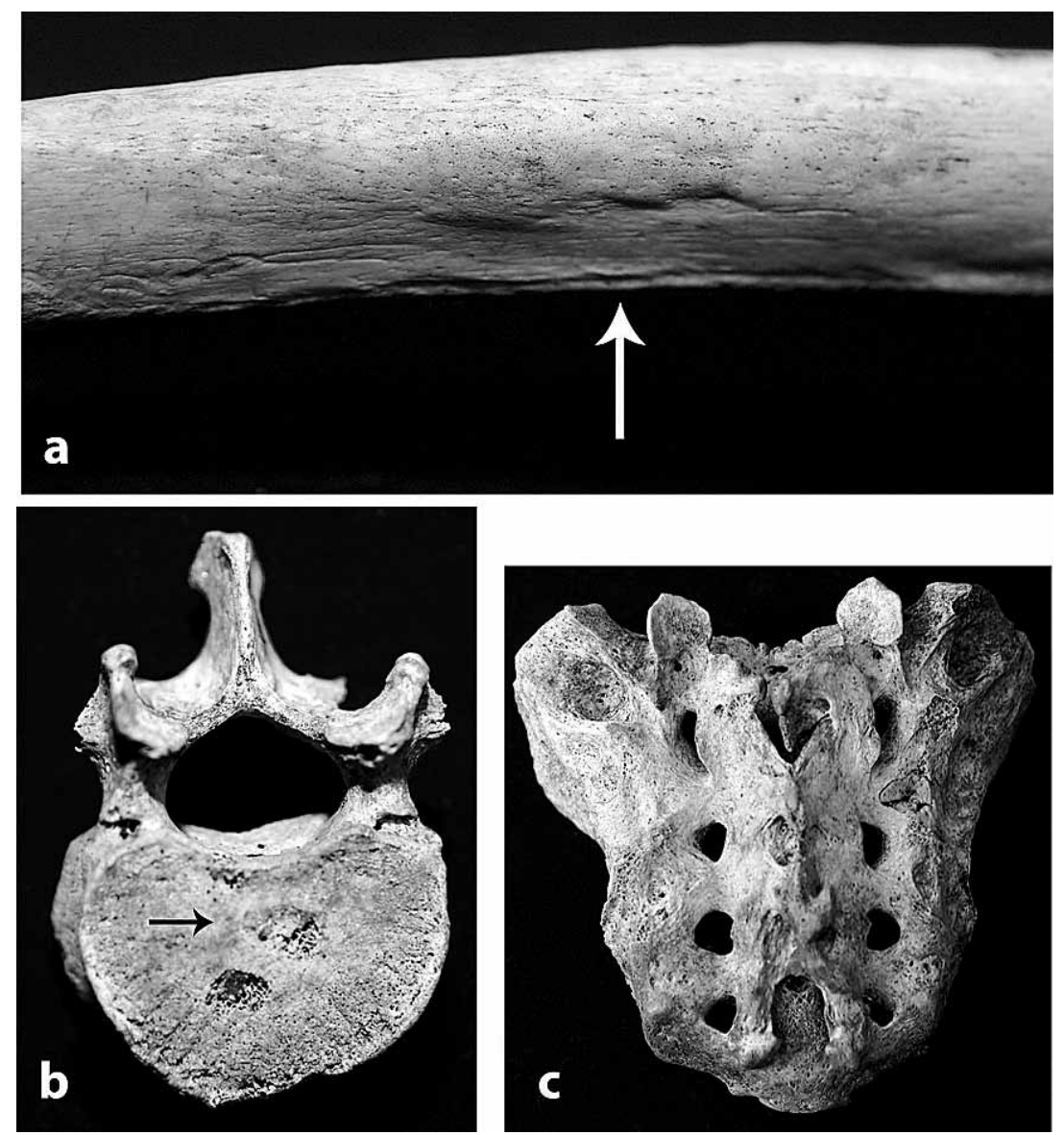

Fig. 5. a) Periostitis en el fémur derecho; b) Nódulo de Schmorl; c) Espina bífida en la primera vértebra sacra (S1).

Las lesiones son unifocales, de forma ovoidal, con destrucción del hueso cortical, de bordes definidos, sin respuesta esclerótica ni colapso estructural. Las lesiones, de apariencia lítica (destructiva), pueden haber sido causadas por un agente infeccioso, o por el desgarro de tejidos blandos (músculo y/o ligamentos).

Las vértebras torácicas 9 y 10 muestran una elongación anormal de las facetas costales articulares en los procesos transversos y el cuerpo vertebral (Fig. 4). Las vértebras torácicas 11 y 12 presentan facetas costales articulares en el proceso transversal izquierdo y derecho, con microporosidad y algunas espículas (T12). La morfología normal de las vértebras torácicas 11 y 12 no incluye facetas articulares en los procesos transversales. Todas las costillas derechas (excepto $\mathrm{N}^{\circ}$ 2) y seis de las costillas izquierdas presentan depositaciones óseas como consecuencia de la osificación del cartílago costal. Estas depositaciones son densas y en algunos casos presentan espículas y macroporosidad. La primera vértebra lumbar (L1) presenta un nódulo de Schmorl (Fig. 5b). El arco vertebral de la primera vértebra sacra (S1) exhibe un desarrollo incompleto que corresponde a espina bífida oculta (Fig. 5c). Los fémures presentan depositaciones óseas de forma alargada e irregular en el aspecto medio-posterior de la mitad superior de la diáfisis. En ambos, la depositación ósea es densa, con microporosidad, sin reabsorción y con bordes escleróticos remodelados que indican que estas lesiones se encontraban inactivas (sanadas) al momento de la muerte (Fig. 5a).

El pie izquierdo presenta una serie de anomalías. El quinto metacarpo muestra una depositación ósea en el tercio proximal de la diáfisis. El hueso 

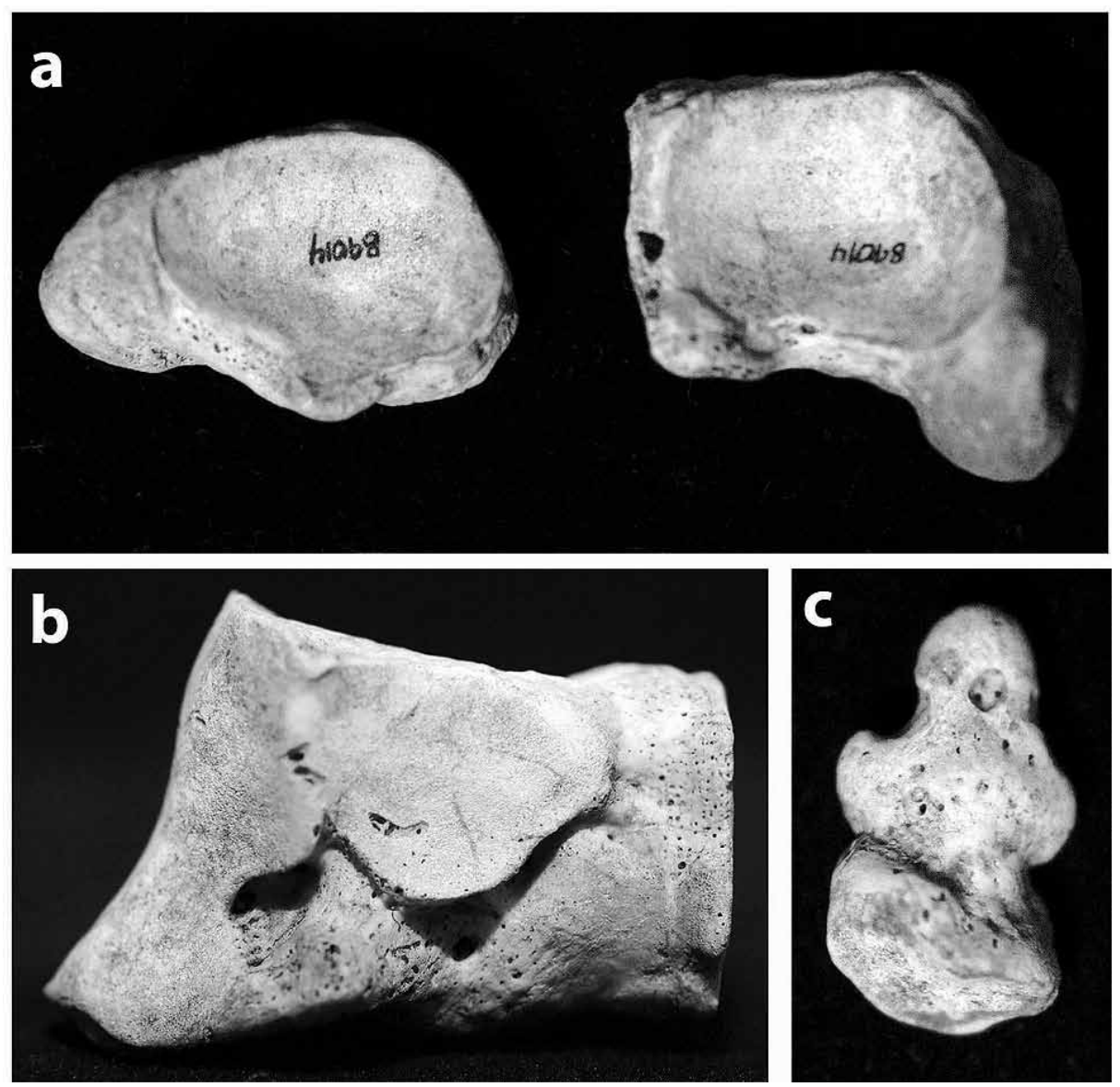

Fig. 6. a) Navicular derecho e izquierdo. Nótese la diferencia en tamaño y forma; b) Cuboide izquierdo de apariencia elongada; c) Falanges distal e intermedia del pie fusionadas.

cortical no está involucrado, la lesión es esclerótica, los bordes se encuentran remodelados, y no se observa porosidad. La lesión parece ser el resultado de una fractura (callo óseo remodelado). El calcáneo presenta una lesión de bordes bien definidos que se extiende desde el sustentaculum tali hacia la faceta articular del cuboide. Esta superficie se encontraba en contacto con el navicular izquierdo. Asimismo, el navicular presenta una lesión en su aspecto anterior, que se encontraba en contacto con una lesión similar en el cuboide y el calcáneo. La forma del navicular izquierdo es anormal (plano y cuadrado) y su borde lateral es más largo que el observado en el navicular derecho (Fig. 6). El cuboide izquierdo también presenta una lesión que se extiende desde la superficie articular para el calcáneo hasta alcanzar la superficie articular para el cuneiforme lateral en el aspecto posterior. La forma del cuboide es larga en compa- ración a la morfología normal de este hueso (Fig. 6b). Tanto el cuboide como el cuneiforme presentan una rotación anormal. Estas lesiones corresponden a tres coaliciones tarsales del tipo calcáneo-navicular, navículo-cuboide, y calcáneo-cuboide (Case y Burnett 2010, Zaw y Calder 2010). Una falange distal e intermedia del pie se encuentran fusionadas, como resultado de una depositación ósea densa en el aspecto dorsal. Dadas las anomalías observadas en el pie izquierdo es posible que ambas falanges correspondan al pie izquierdo (Fig. 6c). La unión de estas falanges corresponde a un sinfalangismo distal. El sinfalangismo distal es un defecto genético poco frecuente que ha sido asociado a una serie de síndromes como el síndrome de Mobius, Marchesani, Nieverlt-Pearlman, Aspert, Poland, y el síndrome de sinostosis múltiple (Gellhoed et al.1969; Castle et al. 1993). 


\section{DISCUSIÓN}

Los hallazgos de restos óseos humanos asociados a contextos arqueológicos del Holoceno medio y, más abundantemente, del Holoceno tardío, son comunes en bahía Inútil. No obstante, la densidad de materiales es muy baja en relación al área muestreada (cf. Martin 2004:122) y la mayor parte de los restos han sido asignados a ocupaciones de cazadores recolectores terrestres, antecesores de los Selk'nam. Estos hallazgos de restos humanos en contextos costeros de Tierra del Fuego, generalmente se presentan como rasgos en sitios arqueológicos asociados a otras actividades (depósitos domésticos), como por ejemplo conchales en los que no es posible distinguir entre los eventos de depositación antrópica y la preservación incidental de los restos (sensu Guichón et al. 2001:106). La distribución espacial diferencial observada entre interior y costa, en cuanto al registro de restos humanos, ha hecho plantear la existencia de factores tafonómicos y formacionales que actúan a escala regional. En el interior la preservación de restos humanos se limita a aquellos casos en los que las prácticas culturales alteran los procesos naturales de desarticulación y meteorización. En la costa, aún ante la ausencia de claras prácticas antrópicas, hay una mejor preservación natural de los restos ya sea en contexto primario o incluso descontextualizados, desarticulados y/o en superficie (Ibid).

En general, la costa norte de la isla registra una preservación diferencial de restos humanos, con predominio de los elementos esqueletales con valores densitométricos altos. La evidencia de bahía Inútil, Primera Angostura y bahía San Sebastián indica que los restos humanos se asocian preferentemente a sitios muy densos, de tipo campamento, con conchales y alta diversidad de líticos y fauna. Estas recurrencias constituyen un modo tafonómico asociado a ámbitos marinos costeros (Martin 2004). En la costa el hallazgo de restos humanos en sitios arqueológicos asociados a actividades no-funerarias es un patrón recurrente. Este patrón hace que los sitios de este tipo sean más predecibles y visibles. Este modelo genera una expectativa de conducta prehistórica asociada a la tendencia a depositar restos humanos en lugares donde se han desarrollado actividades no funerarias (Guichón et al. 2001).
En las zonas interiores la información es escasa, probablemente por un problema de menor visibilidad. El caso emblemático es Cerro de los Onas (ver Constantinescu 1997, 1999; Martin 2004). En Tres Arroyos se conocen locus de hallazgos de huesos aislados y agrupados, pero en contextos de depositación secundarios o terciarios. Sólo un caso de entierro en alero sería un depósito primario (Martin 2006).

Entre los hallazgos costeros similares a cabo Nose destacamos los sitios Marazzi 34 y Marazzi 38 que, como el sitio en cabo Nose, presentan los restos de un individuo adulto asociados con residuos domésticos y un conchal. En ambos casos se identificaron epífisis de guanaco con corte perimetral en superficie, predominando los huesos de este animal en los contextos. Los conchales corresponden a rasgos de mediana densidad y con poca potencia estratigráfica. En el caso de Marazzi 38 el conchal, como en Nose, está siendo erosionado por el mar y ha sido datado en ca. 800 años AP (Constantinescu 2003, Morello et al. 1999, Massone et al. 2003, Massone y Morello 2007). La importante representación de restos de guanaco (epífisis con corte perimetral) y las características de los conchales permite identificar estos sitios con ocupaciones de cazadores terrestres.

Otros sitios en bahía Inútil, y en general en la costa norte de Tierra del Fuego, están asociados a hoyadas de erosión, con diversos materiales arqueológicos expuestos por la acción del viento. Se trata de hallazgos de superficie, con elementos aislados o concentraciones de elementos dispersos, sin articulación y altamente meteorizados (cfr. Martin 2004). En comparación, se presentan como casos únicos las dos sepulturas registradas en el alero Marazzi 1 (Laming-Emperaire et al. 1972) y el caso del Chenque Bahía Felipe, con 5 individuos (Ocampo et al. 2000). Los contextos funerarios más antiguos de la isla se encuentran en conchales y corresponden a uno de los entierros del sitio Marazzi 1 (ca. 5.500 años AP, Morello et al. 2011) y a los restos humanos excavados en el sitio La Arcillosa 2 (5.205 \pm 58 años AP, Salemme et al. 2007).

En bahía San Sebastián, localidad de Las Mandíbulas, son comunes los hallazgos de restos óseos humanos asociados a hoyadas de erosión en el costado oriental de lagunas estacionales, expuestos por la acción del viento (cfr. Martin 
2004). Se trata mayoritariamente de elementos aislados o concentraciones de elementos dispersos, sin articulación, altamente meteorizados y en superficie. También la zona de Los Chorrillos, al sur de la misma bahía, con los sitios de San Genaro, tienen condiciones especiales de visibilidad de estos restos, semejante a todas las situaciones costeras del norte de la isla. Igualmente, se conocen otros casos de hallazgos fortuitos (Martin et al. 2004, Salemme et al. 2007 en Borrazzo et al. 2008), entre otros sitios con restos humanos (por ejemplo, Punta María, Borrero 1986).

El contexto de hallazgo del esqueleto de Cabo Nose es ambiguo en cuanto a su asignación a grupos cazadores terrestres o marítimos. Sin embargo, la ausencia de corte perimetral, el tipo de conchal (denso y con conchillas fragmentadas) y el predominio de huesos de pescado y aves, con escasos restos de guanaco, sugieren su asignación a un modo de vida canoero. Su emplazamiento geomorfológico en una terraza marina muy baja indica que se trataría de un depósito del Holoceno tardío, aspecto confirmado por la datación de un fragmento de la costilla del esqueleto, cuyo resultado dio $980+/-40$ años AP (Beta-283084).

Los análisis de isótopos estables en huesos humanos de cazadores terrestres del norte de Tierra del Fuego indican un predominio de dietas terrestres. Sin embargo, estas dietas terrestres siempre tienen un componente marítimo que está presente de manera sistemática (Barberena 2004). Los estudios isotópicos del individuo de Cabo Nose (13C/12C = -12,3 o/ oo, $15 \mathrm{~N} / 14 \mathrm{~N}=+17,7 \mathrm{o} / \mathrm{oo})$ resultan de una dieta con un claro predominio de la ingesta de proteínas marinas (sensu Borrero et al. 2009). Este dato, en combinación con la información contextual, permite suponer que se trataría de los restos esqueletales de un cazador-recolector especializado en recursos marinos, posiblemente canoero.

El análisis bioantropológico de los restos reveló la presencia de hiperostosis porótica en ambos parietales. Este hallazgo es concordante con otros esqueletos de la región que presentan este tipo de lesiones (Constantinescu 1997, 1999). La hiperostosis porótica es el resultado de la expansión medular provocada por un incremento en la producción de células rojas, gatillada por anemias sufridas durante el periodo de crecimiento y desarrollo (Walker et al. 2009). El incremento en la producción de células rojas se debe a anemias cuyo origen puede ser adquirido (nutricional o infeccioso), o genético (e.g. thalasemia; Ortner 2003, Blom et al. 2005). Tradicionalmente la hiperostosis porótica ha sido considerada el resultado de anemias ferroprivas (Stuart-MacAdam 1992, Constantinescu 1997, 1999, Blom 2005). Sin embargo, nuevos estudios indican que las dietas ferroprivas inhiben la expansión medular de la cual resultan este tipo de lesiones. Por lo tanto, sólo anemias megaloblásticas -aquellas que son el resultado de una inhibición en la síntesis del ADN y que alteran la producción y duración de las células rojas- pueden provocar las lesiones óseas que caracterizan a la hiperostosis porótica (Walker et al. 2009).

Las poblaciones nativas de las Américas no sufren de anemias genéticas megaloblásticas (Abolghazemi et al. 2007, Kulozik et al. 1986, Makhoul et al. 2005, Rund et al. 2004, Agharwal 2000, Iolascon et al. 2000). Por lo tanto, la presencia de hiperostosis porótica en el individuo N 89014 sería el resultado de una anemia megaloblástica adquirida. Las anemias megaloblásticas pueden ser producidas por deficiencias nutricionales de las vitaminas B12 (colabamina), B9 (folato), $\mathrm{D}_{3}$ (cholecalciferol) o C (ácido ascórbico, Ortner 2003, Walker et al. 2009). El individuo $N^{\circ} 89104$ no presenta evidencia de deficiencias en vitaminas D3 (raquitismo) o C (escorbuto, Ortner 2003).

Deficiencias en vitaminas B12 y B9 son las causas más comunes de anemias megaloblásticas (Walker 2009, Caudill 2010). Walker et al. (2009) indican que las lesiones hipersostóticas observadas en poblaciones pasadas se deben a deficiencias en vitamina B12. La causa más común de deficiencia en vitamina $\mathrm{B} 12$ es el consumo de dietas pobres en vitamina B12 o la mala absorción (Allen 2008). La vitamina B12 (cobalamina) se encuentra sólo en alimentos de orígen animal. Niveles bajos de vitamina B12 se deben a dietas vegetarianas, o pobres en alimentos animales. Estos cuadros anémicos se agudizan en casos de infecciones intestinales causadas por parásitos como el Diphyllobotrhium latum (cestodo). Estos parásitos son transmitidos por peces de aguas frias que son ingeridos crudos o mal cocidos (Allen 2008). Dado que la dieta de estas poblaciones australes era rica en alimentos de origen animal, y debido a que los moluscos como las almejas y choros se encuentran entre los pro- 
ductos más ricos en vitamina B12 (USDA 2010), es improbable que la hiperostosis porótica observada en este individuo haya sido el resultado de una dieta pobre en recursos animales.

Otra posible causa de anemia megaloblástica de orígen adquirido es la deficiencia de vitamina B9 (folato). Las fuentes dietéticas de folato se encuentran en vegetales de hojas verdes (e.g. espinacas), las legrumbres y algunas frutas (Allen 2008, USDA 2010). Las condiciones ambientales de la zona, la dieta consumida por las poblaciones que habitaban esta region -que se caracterizaba por una alta ingesta de alimentos de origen animal y bajo consumo de vegetales (Garson 1886, Butland 1957)-, indican que la carencia de folatos es la causante más posible de la hiperostosis porótica observada en este individuo. La ingesta de alimentos marinos mal cocidos (ver descripciones en Garson 1886, Holgate 1961) podría haber generado una carga parasitaria intestinal que habría agudizado el cuadro anémico (Allen 2008).

El desgaste dental observado en este individuo es moderado. El chipping indica la presencia de partículas duras en la dieta, que en este caso corresponderían a granos de arena y/o pedazos de conchas. La presencia de una dieta abrasiva que incluía partículas duras es característica de poblaciones cazadoras recolectoras. La baja ingesta de alimentos ricos en carbohidratos es también común en poblaciones cazadoras, lo que explica el grado de abrasión, la ausencia de caries, la escaza depositación de tártaro dental y el desarrollo moderado de la reabsorción alveolar. Las características observadas en la patología dental de este individuo sigue el patrón observado en cazadores-recolectores costeros de la zona norte de Chile (Alfonso et al. 2007). La presencia de hipoplasias del esmalte indica que el individuo $\mathrm{N}^{\circ} 89014$ sufrió eventos de estrés agudo durante su niñez. La práctica de lactancia prolongada entre los grupos fueguinos (Gusinde 1982) podría explicar la ocurrencia de estrés a edades más tardías en comparación con otros grupos cazadores (Alfonso et al. 2007).

El húmero izquierdo presenta tres lesiones. Las lesiones en el segmento superior (surco intertubecular) corresponden al sitio de inserción del pectoral mayor, músculo encargado de abducir y rotar el brazo (Hawkey y Merbs 1995, White y Folkens 2000). La lesión ubicada en la Fosa Radial corresponde al área que recibe la cabeza del radio durante la flexión máxima del antebrazo (Hawkey y Merbs 1995, White y Folkens 2000). Estas lesiones están asociadas con movimientos de flexión y rotación medial del brazo. La posibilidad de que estas lesiones hayan sido causadas por un agente infeccioso es mínima dada su ubicación y la ausencia de respuesta esclerótica. Este tipo de lesiones, también conocidas como entesopatías, son el resultado de actividades que producen microtrauma en la zona afectada. Desgarros en las fibras musculares, que adhieren el músculo al periosteo, son producto de una tensión habitual y prolongada. Estos desgarros interrumpen el flujo sanguíneo, lo que lleva a la muerte de las células óseas y la aparición de lesiones de aspecto lítico (Hawkey y Merbs 1995).

Constantinescu (1997, 2001) intentó relacionar indicadores morfofuncionales con actividades específicas como el uso del arco y la flecha, o la actividad de remar (Constantinescu 2001). Sin embargo, la interpretación de las inserciones musculares en la identificación de actividades específicas es cuestionable (Cardoso y Henderson 2010). La inserciones musculares son complejas, los músculos responden a una serie de estreses bio-mecánicos y nuestro conocimiento e imaginación de las tareas y/o actividades ejecutadas por individuos prehistóricos es limitado (Robb 1998). Un estudio estadístico a nivel poblacional podría identificar variaciones sociales en la carga física y la ejecución de actividades especializadas, ya que la información etnográfica en la zona es detallada (i.e. Gusinde 1982, Hawkey y Merbs 1995, Robb 1998). Un estudio de este tipo debe considerar el efecto de la talla, el sexo y la edad en la formación de marcadores morfofuncionales, lo cual requiere de un análisis a nivel grupal (Weiss 2007, Lieverse et al. 2009, Cardoso y Henderson 2010, Villote et al. 2010).

La formación de facetas costales elongadas (T9 y T10), y extranumerarias (T11 y T12), así como la presencia de entesopatías (espículas) y artropatía erosiva (porosidad) responde a actividades en las que este individuo acarreaba cargas pesadas. La osificación del cartílago costal se asocia al proceso de envejecimiento y no son indicativas de patologías o actividades (Rejtarová et al. 2009). El nódulo de Schmorl en L1 es el resultado de una hernia del disco intervertebral. Los nódulos de Schmorl son comunes en individuos mayores de 45 años (Aufderheide y 
Rodríguez-Martín 1998). Sin embargo, el individuo $N^{\circ} 89014$ era joven y la presencia del nódulo en L1 indica, nuevamente, que éste ejecutó actividades físicas que producían estrés mecánico en la columna vertebral. Otros estudios (Constantinescu 1997) y descripciones etnográficas de grupos canoeros y cazadores del interior (Gusinde 1982) indican que tanto hombres como mujeres transportaban cargas pesadas en la zona lumbar. Este estrés, mecánico y repetitivo, puede producir hernias en el disco intervertebral que invaden el cuerpo vertebral, generando una reacción inmunológica que lleva a la destrucción localizada del hueso esponjoso y la consecuente formación del nódulo (Zhang et al. 2010). Los nódulos de Schmorl se asocian con dolor de espalda, el cual posiblemente afectó al individuo N ${ }^{\circ} 89014$ (Peng et al. 2003, Wililams y Manek 2007, Faccia y Williams 2008).

El arco vertebral de la primera vértebra sacra (S1) presenta una fusión incompleta que corresponde a espina bífida oculta (rachischisis). La espina bífida es el más común de los defectos congénitos del tubo neural, y la variente oculta es la más frecuente (Saluja 1988, Auderheide y Rodríguez-Martín 1998, Fletcher y Brei 2010). Este desorden neurogenético tiene una etiología compleja que incluye factores genéticos y medioambientales (Harris y Juriloff 1999, Fletcher y Brei 2010, Reddy et al. 2010, Silva-Pinto et al. 2010).

Tradicionalmente la espina bífida oculta ha sido considerada asintomática (ver revisión en Fletcher y Brei 2010). Sin embargo, nuevos estudios indican que ésta afecta el control del equilibrio, porque altera los sensores vinculados a los músculos extensores de la espalda (Harris y Juriloff 1997, Chang y Ku 2007) y produce complicaciones urológicas (e.g. incontinencia urinaria, Fidas et al. 1989, Hall y Hall 1989). Individuos con espina bífida oculta suelen presentar rotación lateral de las piernas (Wilkinson y Sedwick 1988) y/o deformidades del pie (Zambito et al. 2008). Por ende, es posible que las anomalías observadas en el pie izquierdo del individuo puedan estar asociadas a las espina bífida oculta, ya que ambas condiciones son congénitas. El individuo $\mathrm{N}^{\circ}$ 89014 rotaba el pie al caminar, como resultado de las coaliciones tarsales presentes en el pie izquierdo (Fig. 6). La rotación del pie y una capacidad de equilibrio disminuída explicarían la presencia de fracturas, de naturaleza accidental, en el pie. La etiología de la espina bífida es compleja e incluye factores medioambientales y genéticos (Fletcher y Brei 2010, Reddy et al. 2010, Silva-Pinto et al. 2010). La carencia de folatos se encuentra entre los factores medioambientales que provocan la espina bífida (Caudill 2010)․․ Las anemias megaloblásticas en poblaciones actuales cuyo modo de vida tradicional era nomádico, y que tiene una dieta rica en productos animales pero pobre en vegetales, se asocian en un $75 \%$ con deficiencia de folato (Akilzhanova et al. 2006). Descripciones etnográficas de los grupos que habitaron la región señalan que la dieta estaba constituída por alimentos de orígen animal con escasa contribución de vegetales (Butland 1957, Holdgate 1961). Las coaliciones tarsales son defectos de orígen congénitos que pueden restringir o eliminar el movimiento del pie y que provocan dolor (Kernbach 2010, Zaw y Calder 2010). Las coaliciones tarsales se asocian, en ocasiones, a otros defectos como el pie equino y el pie plano espástico (Spero et al. 1994, Kernbach 2010, Zaw y Calder 2010). La presencia de más de una coalición tarsal en el mismo pie es poco frecuente (Masquijo y Jarvis 2010). El pie equino se asocia, en ocasiones, a las dysraphias vertebrales, como la espina bífida y tambien con las coaliciones tarsales (Callahan 1980, Alexander et al. 1999). El pie equino, sin embargo, presenta características anatómicas, como la reducción en el tamaño del navicular (Blakeslee 1997), que no coinciden con la morfología de los huesos tarsales del individuo $\mathrm{N}^{\circ}$ 89104. Sin embargo, no es posible descartar del todo esta posibilidad, ya que el término "pie equino" se utiliza para describir una serie de defectos del pie (Kyzer y Stark 1995), algunos de los cuales presentan similitudes con los observados en este caso (Wallander 2010).

El sinfalangismo distal es resultado de un desorden genético infrecuente. Su presencia se asocia, en ocasiones, con coaliciones tarsales (Geelhoed et al. 1969, Castle et al. 1993). El sinfalagismo distal es un rasgo genético autosómico dominante, que puede ser utilizado en la identificación de individuos que, en términos genéticos, pertenecen a la misma familia (Geelhoed et al. 1969, Castle et al. 1993,

\footnotetext{
1 Las harinas enriquecidas con folatos, en la población Chilena actual, han disminuido significativamente la frequencia de defectos congénitos, incluyendo la espina bífida (LópezCamelo et al. 2005; Hertrampf y Cortéz 2008)
} 
Case y Burnett 2010). Por lo tanto, las coaliciones tarsales y el sinfalangismo distal observado en este individuo serían consecuencia de una condición genética que no necesariamente se relaciona con la presencia de espina bífida oculta. Entre los síndromes asociados a la presencia de sinfalangismo distal, los síndromes de Mobious, Marchesani, Poland, y Nievergelt-Pearlman pueden ser descartados debido a la ausencia de defectos faciales, craneales, asimetría ósea y baja estatura en el individuo de Cabo Nose.

Las depositaciones óseas periosteales en los fémures se deben a una hemorragia (hematoma subperiostio) producida por un estresor traumático excesivo, procesos infecciosos o tumores (Ortner 2003). Las depositaciones óseas periosteales, de orígen inespecífico, en los huesos largos, se encuentran entre las anormalidades esqueletales más comunes (Ibid.). No se encontró evidencia de tumores asociados y la apariencia localizada de las lesiones indica que éstas no respondían a un estrés sistémico (Weston 2008). La naturaleza bilateral y simétrica de estas lesiones indica que éstas tuvieron un origen traumático o que se debieron a úlceras localizadas. La periostitis traumática se desarrolla debido a traumas crónicos generados por actividades ejecutadas de manera repetitiva. Además, si estas lesiones fueron causadas por úlceras es posible que, dada su naturaleza bilateral, ellas hayan resultado de algún tipo de actividad.

El análisis de la estatura entrega un rango que varía entre los 153 y los $172 \mathrm{~cm}$ (Tabla 3). Las estimaciones basadas en las medidas de la tibia, que son más acertadas, indican que la estatura del individuo era de $\approx 164,6 \mathrm{~cm}$. Estimaciones basadas en las fórmulas desarrolladas por Trotter y Glesser (1952, 1958), cuyas muestras eran pequeñas y sobre la cual existen dudas respecto a la metodología utilizada, deben ser consideradas con precaución (Jantz et al. 1994). Cálculos basados en las fórmulas mesoamericanas (del Angel y Cisneros 2004) dan resultados de menor estatura (Tabla 3 ), aunque es posible que las poblaciones mesoamericanas sean más bajas que las fueguinas. Lamentablemete, las muestras que constituyen la base de éstas fórmulas no incluyen nativos de la zona magallánica, por lo cual éstos cálculos son sólo una aproximación (ver Konigsberg et al. 1998). Ya que las piernas de algunos de los grupos australes eran cortas en relación al largo del torso (Garson 1886, Furlong 1933), estos cálculos posiblemente subestiman la estatura de este individuo. Sin embargo la estatura calculada es similar a la obtenida en otros estudios de restos humanos de la región (Constantinescu 1997) y es similar a las estaturas descritas en algunos reportes etnológicos de la zona (Garson 1886).

\section{CONCLUSIONES}

El salvataje y estudio sistemático del individuo de cabo Nose revela aspectos culturales y biológicos de las poblaciones fueguinas prehistóricas. El individuo del salvataje correspondería a un adulto joven, de sexo masculino, con una datación directa que lo ubica en el primer milenio de nuestra era. La localización espacial del hallazgo, en una zona de superposición de áreas de circulación de grupos cazadores terrestres (antecesores de los Selk'nam) y canoeros (alacalufes), genera una interrogante sobre la adscripción cultural del individuo. La cuestión de la diferenciación física y cultural de los dos grandes grupos identificados en tiempos etnográficos por un modo de vida nómade pedestre (cazadores de guanaco) o marítimo (canoeros, cazadores de lobos marinos) es un reto metodológico que requiere de la consideración de múltiples vías de aproximación.

La información contextual del sitio de hallazgo y el análisis isotópico del esqueleto humano indican un claro predominio de dieta marítima. Otros proxis como los cálculos de rango de estatura probable, sumado a las observaciones realizadas sobre patologías producidas por el estrés mecánico de actividades físicas recurrentes, no son suficientemente específicos como para dirimir si se trata de un individuo cazador-recolector terrestre o de un canoero. Sin embargo, la información sobre subsistencia sugiere que el individuo de Cabo Nose pertenecía a un grupo cuyo modo de vida era canoero.

La evaluación bioantropológica del esqueleto ha entregado interesantes datos sobre factores dietarios que podrían estar influyendo en el estado de salud general de estas poblaciones fueguinas. En este caso este se discute la presencia de un cuadro de anemia megaloblástica adquirida y relacionada con la presencia de hiperostosis porótica, espina bífida y coalisiones tarsales asociadas. Aunque en otras poblaciones costeras la hiperostosis porótica ha sido considerada como el resultado de infecciones 
parasitarias (Walker 1986, Blom et al. 2005), la dieta, el medioambiente, así como la presencia de espína bífida oculta sugieren que la deficiencia de folatos en la dieta (vitaminas B9), asociados al bajo consumo de vegetales verdes y una dieta basada en carne animal, es la explicación más plausible sobre estado de salud del individuo de Cabo Nose. Por otra parte la presencia de otros dos defectos congénitos (coaliciones tarsales y sinfalangismo distal) merecen mayor investigación en la zona. Ya que el sinfalagismo distal es heredado en forma autosómica y que su expresión es dominante. El estudio sistemático de este tipo de defectos en los restos óseos humanos en la zona puede entregar importante información sobre las relaciones genéticas entre los individuos hayados en los sitios arqueológicos de la región.

\section{AGRADECIMIENTOS}

Este salvataje y el estudio bioantropológico fueron realizados en el marco del proyecto FONDECYT 1060020.

Agradecemos la participación de Pedro Cárdenas y Gabriel Bahamonde en las labores de terreno. La Dra. Fabiana Martin evaluó algunos aspectos tafonómicos y determinó la presencia de marcas de cánidos. Bretton T. Giles generosamente colaboró en la composición de las figuras 4-6. Agradecemos también a Scott Burnett por su ayuda en la identificación de las coaliciones tarsales.

\section{BIBLIOGRAFÍA}

AKILZHANOVA, A., TAKAMURA, N., AOYAGI, K., KARAZHANOVA, L., y YAMASHITA, S. 2006. Folic Acid Deficiency: Main Etiological Factor of Megaloblatic Anemia in Kazakhstan? American Journal of Hematology 81: 471.

ALEXANDER, M., ACKMAN, J.D., y KUO, K.N. 1999. Congenital Idiopathic Clubfoot. Orthopaedic Nursing 18: 47-57.

ALFONSO M.P., STANDEN, V.G., y CASTRO, M.V. 2007. The adoption of agriculture among northern Chile populations in the Azapa Valley 9,000-1,000 BP. En: Ancient Health. Skeletal indicators of agricultural and economic intensification. Cohen MN, Crane-Kramer GMM, editores. Pp 113-129. University of Florida Press, Gainsville.

ALLEN, L.H. 2008. Causes of Vitamin B12 and Folate Deficiency. Food and Nutrition Bulletin 29 (Suppl. 2): S20-S34.
AUFDERHEIDE, A.C., y RODRIGUEZ-MARTIN, C. 1998. The Cambridge Encyclopedia of Human Paleopathology. Cambridge University Press, Cambridge.

BARBERENA, R. 2004. Arqueología e Isótopos estables en Tierra del Fuego. En, Temas de Arqueología. Arqueología del norte de la Isla Grande de Tierra del Fuego. L. Borrero y R. Barberena editores. pp. 135-169. Editorial Dunken, Buenos Aires.

BINFORD, L. 1981. Bones. Ancient Men and Modern Myths. Academic Press, New York.

BLAKESLEE, T.J. 1997. Congenital Idiopathic Talipes Equinovarus (Clubfoot). Pediatric Podiatry 14: 9-56.

BLOM, D.E., BUIKSTRA, J.E., KENG, L., SHOREMAN, E., y STEVENS-TUTTLE, D. 2005. Anemia and Childhood Mortality: Latitudinal Patterning Along the coast of Pre-Columbian Perú. American Journal of Physical Anthropology 127 (2): 152-169.

BORRERO, L.A. 1986. La economía prehistórica de los habitantes del norte de la Isla Grande de Tierra del Fuego. Tesis Doctoral, Universidad de Buenos Aires, Buenos Aires.

BORRERO, L., BARBERENA, R., FRANCO, N., CHARLIN, J., y TYKOT, R.H. 2009. Isotopes and Rocks: Geographical Organization of Southern Patagonian Hunter-Gatherers. International Journal of Osteoarchaeology 19:309-327.

BROOKS, S.T. y SUCHEY, J.M. 1990. Skeletal Age Determination Based on the Os Pubis: A Comparison of the Acsádi-Nemeskéri and Suchey-Brooks Methods. Human Evolution 5(3): 227-238.

BROTHWELL, D.R. 1981. Digging Up Bones. Cornell University Press, Ithaca, New York.

BUIKSTRA, J.E. y UBELAKER, D.H. 1994. Standards for Data Collection from Human Skeletal Remains. Proceedings of a Seminar at The Field Museum of Natural History. Arkansas Archaeological Survey Research Series $N^{\circ} 44$. Arkansas Archaeological Survey, Fayeteville, Arkansas.

BUTLAND, G.I. 1957. The Human Geography of Southern Chile. The Institute of British Geographers Publication $\mathrm{N}^{\circ}$ 24, London.

CALLAHAN, R.A. 1980. Talipes Equinovarus Associated with an Absent Posterior Tibial Tendon and Tarsal Coalition. Clinical Orthopaedics and Related Research 146: 231-233.

CARDOSO, F.A. y HENDERSON, C.Y. 2010. Enthesopathy Formation in the Humerus: Data from Known Age-at-Death and Known Occupation Skeletal-Collections. American Journal of Physical Anthropology 141:550-560.

CASE, D.T., y BURNETT, S.E. 2010. Identification of Tarsal Coalition and Frequency Estimates from Skeletal Samples. International Journal of Osteoarchaeology (ahead of print). DOI: 10.1002/0a.1228. 
CASTLE, J.E., BASS, S., y KANAT, I.O. 1993. Hereditary Symphalangism with Associated Tarsal Synostosis and Hypophalangism. Journal of the American Podiatric Medical Association 83: 1-9.

CAUDILL, M.A. 2010. Folate bioavailability: implications for establishing dietary recommendations and optimizing status. Journal of Clinical Nutrition 91 (Suppl): 1455S1460S.

CHANG, S-T. y KU, C-H. 2007. Postural Sway at Ground and Bevel Levels in Subjects with Spina Bifida Occulta. European Spine Journal 16: 756-769.

CONSTANTINESCU, F. 1997. Hombres y Mujeres del Cerro Los Onas: Presentes, Ausentes... Los Relatos de sus Huesos. Anales del Instituto de la Patagonia, Serie Ciencias Humanas 25: 59-74.

CONSTANTINESCU, F. 1999. Evidencias Bioantropológicas para Modos de Vida Cazador Recolector Terrestre y Marítimo en los Restos Óseos Humanos de la Tierra del Fuego. Anales del Instituto de la Patagonia, Serie Ciencias Humanas 27: 137-174.

CONSTANTINESCU, F. 2001. Canal Maule y Punta Santa Ana: El Habitus Cazador Recolector Marítimo Femenino (Patrones Óseos Característicos del Modo de Vida Canoero en el Extremo Sur de Chile). Anales del Instituto de la Patagonia Serie Ciencias Humanas 29: 163-181.

CONSTANTINESCU, F. 2003. Bioantropología de Bahía Inútil, Tierra del Fuego. En: Informe de Avance, 1er Año, Proyecto FONDECYT 1020004. MS.

DEL ANGEL, A. y CISNEROS, C.H. 2004. Technical Note: Modification of Regression Equations Used to Estimate Stature in Mesoamerican Skeletons. American Journal of Physical Anthropology 125: 264-265.

FACCIA, K.J. y WILLIAMS, R.C. 2008. Schmorl's Nodes: Clinical Significance and Implications for the Bioarchaeological Record. International Journal of Osteoarchaeology 18: 28-44.

FIDAS, A., MACDONALD, H.L., ELTON, R.A., MCINNES, A., WILD, S.R., y CHISHOLM, G.D. 1989. Prevalence of Spina Bifida Occulta in Patients with Functional Disorders of the Lower Urinary Tract and its Relation to Urodynamic and Neurophysiologic Measurements. British Medical Journal 298: 356-359.

FLETCHER, J.M. y BREI, T.J. 2010, Introduction: Spina Bifida a Multidisciplinary Perspective. Developmental Dissabilities Research 16: 1-5.

FURLONG, C.W. 1933. Exploration in Tierra del Fuego and the Fueguian Archipelago. The Geographical Journal 81 (3): 211-224.
GARSON, J.P. 1886. On the Inhabitants of Tierra del Fuego. The Journal of the Anthropological Institute of Great Britain and Ireland 15: 141-160.

GEELHOED, G.W., NEEL, J.V., y DAVIDSON, R. 1969. Symphalangism and Tarsal Coalitions: A Hereditary Syndrome. The Journal of Bone and Joint Surgery 51 B: 278-289.

GOODMAN, A.H., y ROSE, J.C. 1990. Assessment of Sytemic Phisiological Perturbation from Dental Enamel Hypoplasia and Associated Histological Structures. American Journal of Physical Anthropology 33 (S11): 59-110.

GUICHON, R., BARBERENA, R., y BORRERO, L. 2001. ¿Dónde y cómo aparecen los restos óseos humanos en Patagonia austral? Anales del Instituto de la Patagonia, Serie Ciencias Humanas 29: 103-118.

GUSINDE, M. 1982. Los Indios de la Tierra del Fuego. Centro Argentino de Etnología Americana. Consejo Nacional de Investigaciones Científicas y Técnicas, Buenos Aires.

HALL, P.N. y HALL, M.H. 1989. Spina Bifida Occulta and the Functional Disorders of the Urinary Tract. British Medical Journal 298: 755.

HARRIS, M.J., y JURILOFF, D.M. 1999. Mini Review: Toward Understanding Mechanisms of Genetic Neural Tube Defects in Mice. Teratology 60: 292-305.

HAWKEY, D.E., y MERBS, C.F. 1995. Activity-Induced Musculoskeletal Stress Marker (MSM) and Subsistence Strategy Changes Among Ancient Hudson Bay Eskimos. International Journal of Osteoarchaeology 5: 324-338.

HERTRAMPF, E., y COTES, F. 2008. National Food-Fortification Program with Folic Acid in Chile. Food and Nutrition Bulletin 292 (Supl): S231-S237.

HOLGATE, M.W. 1961. Man and Environment in the South Chilean Islands. The Geographical Journal 127 (4): 401-414.

IOLASCON, A., SERVEDIO, V., CARBONE, R., TOTARO, A., CARELLA, M., PERROTTA, S., WICKRAMASINGHE, S.N., DELAUNAY, J., HEIMPEL, H., y GASPARINI, P. 2000. Geographic Distribution of CDA-II: Did a Founder Effect Operate in Southern Italy? Haematologica 85 (5): 470-474.

JANTZ, R.L., HUNT, D.R. y MEADOWS, L.1994. Maximum Length of the Tibia: How did Trotter Measured It? American Journal of Physical Anthropology 93: 525-528.

KERNBACH, K.J. 2010. Tarsal Coalitions: Etiology, Diagnosis, Imaging, and Stigmata. Clinical Podiatric Medical Surgery 27: 105-117.

KONIGSBERG, L.W., HENS, S.M., JANTZ, L.M., y JUNGERS, W.L. 1998. Stature Estimation and Calibration: Bayesian and Maximum Likelihood Perspectives on Physical 
Anthropology. Yearbook of Physical Anthropology 41: 65-92.

KULOZIK, A.E., WAINSCOAT, J.S., SERJEANT, G.R., KAR, B.C., AL-AWAMY, B., ESSAN, G.J.F., FALUSI, A.G., HAQUE, S.K., HILALI, A.M., KATE, S., RANASINGHE, W.A.E.P., y WEATHERALL, D.J. 1986. Geographical Survey of $\aleph^{\text {s-Globin }}$ Gene haplotypes: Evidence for an Independent Asian Origin of the Sickle Cell Mutation. American Journal of Human Genetics 39: 239-244.

KYZER, S.P., y STARK, S.L. 1995. Congenital Idopathic Clubfoot Deformities 61: 492-506.

LAMING-EMPERAIRE, A., LAVALLÉE, D., y HUMBERT, R. 1972 Le Site de Marazzi en Terre de Fue. Objets et Mondes 12(2): 225-244.

LIEVERSE, A.R., BAZALIISKII, V.I., GORIUNOVA, O.I., y WEBER, A.W. 2009. Upper-Limb Musculoskeletal Stress Markers Among Middle-Hoocene Foragers of Siberia Cis-Baikal Region. American Journal of Physical Anthropology 138: 458-472.

LÓPEZ-CAMELO, J.S., CASTILLA, E.E., y ORIOLI, I.M. 2010. Folic Acid Flour Fortification: Impact on the Frequencies of 52 Congenital Anomaly Types in Three South American Countries. American Journal of Medical Genetics Part A 152A: 2444-24458.

LOVEJOY, C.O., MEINDL, R.S., PRYZBECK, T.R. y MENSFORTH, R.P. 1985. Chronological Metamorposis of the Auricular Surface of the Ilium: A New Method for the Determination of Age at Death. American Journal of Physical Anthropology 68(1): 15-28.

MAKHOUL, N.J., WELLS, R.S., KASPAR, H., SHBAKLO, H., TAHER, A., CHAKAR, N. y ZALLOUA, P.A. 2005. Genetic Heterogeneity of Beta-Thalassemia in Lebanon Reflects Historic and Recent Population Migration. Annals of Human Genetics 69 (Pt1): 55-66.

MARTIN, F. 2004. Capítulo 5. Tendencias tafonómicas en el registro óseo humano del Norte de Tierra del Fuego. En: Temas de Arqueología. Arqueología del norte de la Isla Grande de Tierra del Fuego, editado por L. Borrero y R. Barberena. Pp. 107-133. Editorial Dunken, Buenos Aires.

MARTIN, F. 2006. Carnívoros y huesos humanos de FuegoPatagonia. Aportes desde la Tafonomía Forense. Sociedad Argentina de Antropología, Buenos Aires.

MARTIN, F., BARBERENA, R., y GUICHÓN, R. 2004. Erosión y restos humanos. El caso de la localidad Chorrillos, Tierra del Fuego. Magallania 32:125-142.

MASQUIJO, J.J, y JARVIS, J. 2010. Associated Talocalcaneal and Calcaneonavicular Coalitions in the Same Foot. Journal of Pediatric Orthopaedics B 19: 507-510.
MASSONE, M., y MORELLO, F. 2007. Los cetáceos en el mundo selk'nam: una evaluación arqueológica. En: Arqueología de Fuego-Patagonia. Levantando piedras, desenterrando huesos... y develando arcanos. Editado por F. Morello, M. Martinic, A. Prieto y G. Bahamonde. Pp. 709-721. Ediciones CEQUA, Punta Arenas.

MASSONE, M., MORELLO, F., PRIETO, A., SAN ROMÁN, M., MARTIN, F., y CÁRDENAS, P. 2003. Sitios arqueológicos, restos de cetáceos y territorios locales selk'nam en bahía Inútil, Tierra del Fuego. Magallania 31:45-60.

MEINDL, R.S. y LOVEJOY, C.O. 1985. Ectocranial Suture Closure: A Revised Method for the Determination of Skeletal Age at Death Based on the Lateral-Anterior Suture. American Journal of Physical Anthropology 68 (1): 57-66.

MEINDL, R.S. y LOVEJOY, C.O. 1989. Age Changes in the Pelvis. Implications for Paleodemography. En: Age Markers in the Human Skeleton (Ed. M. Y. Iscan), pp. 137-168. Charles C. Thomas, Springfield, Illinois.

MORELLO, F., CONTRERAS, L. y SAN ROMÁN, M. 1999. La Localidad de Marazzi y el Sitio Arqueológico Marazzi 1; una reevaluación. Anales del Instituto de la Patagonia, Serie Ciencias Humanas 27:183-197.

MORELLO, F., BORRERO, L., MASSONE, M., STERN, C., GARCÍA-HERBST, A., MCCULLOCH, R., ARROYOKALIN, M., CALÁS, E., TORRES, J., PRIETO, A., MARTINEZ, I., BAHAMONDE, G., y CÁRDENAS, P. 2011. Hunter-gatherers, biogeographic barriers and the development of human settlement in Tierra del Fuego. Antiquity (en prensa).

OCAMPO, C., RIVAS, P. y ASPILLAGA, E. 2000. Chenque en Bahía Felipe, Costa Noroccidental de Tierra del Fuego. Anales del Instituto de la Patagonia, Serie Cs. Humanas 28: 215-223.

ORTNER, D.J. 2003. Identification of Pathological Conditions in Human Skeletal Remains. Academic Press, New York.

PENDERSON, P.O. 1993. The East Greenland Eskimo Dentition. Med om Gromland 142: 1-256.

PENG, B., WU, W., HOU, S., SHANG, W., WANG, X., y YANG, Y. 2003. The pathogenesis of Schmorl's nodes. The Journal of bone and Joint Surgery [Br] (85B); 879-882.

REDDY, P.A., RAJAGOPAL, G., HARINARA, C.V., VANAJA, V., RAJASEKHAR, D., SURESH, V., y SACHAN, A. 2010. High Prevalence of Associated Birth Defects in Congenital Hypothyroidism. International Journal of Pediatric Endocrinology 2010: 1-5.

REJTAROVÁ, O., HEJNA, P., SOUKUP, T., y KUCHAR, M. 2009. Age and Sexually Dimorphic Changes in Costal 
Cartilages. A Preliminary Microscopic Study. Forensic Science International 193: 72-78.

RITZMAN, T.R., BAKER, B.J., y SCHWARTZ, G.T. 2008. A Fine Line: A Comparison of Methods for Estimating Ages of Linear Enamel Hypoplasia Formation. American Journal of Physical Anthropology 135: 348-361.

ROBB, J.E. 1998. The Interpretation of Skeletal Muscle Sites: A Statistical Approach. International Journal of Osteoarchaeology 8: 363-377.

RUND, D., FILON, D., JACKSON, N., ASHER, N., ORON-KARNI, V., SACHA, T., CZEKALSKA, S., y OPPENHEIM, A. 2004. An Unexpected High Frequencyof Heterozygosity for Alpha-Thalassemia in Ashkenazi Jews. Blood Cells Molecular Disorders 33 (1): 1-3.

SALEMME, M., BUJALESKY, G., y SANTIAGO, F. 2007. La Arcillosa 2: la ocupación humana durante el Holoceno medio en río Chico, Tierra del Fuego, Chile. En: Arqueología de Fuego-Patagonia. Levantando piedras, desenterrando huesos... y develando arcanos, F. Morello, M. Martinic, A. Prieto y G. Bahamonde editores. Pp. 723-736. Ediciones CEQUA, Punta Arenas.

SALUJA, P.G., 1988. The Incidence of Spina Bifica Occulta in Historic and Modern London Populations. Journal of Anatomy 158: 91-93.

SCOTT, E.C. 1979. Dental Scoring Technique. American Journal of Physical Anthropology 51(2): 213-218.

SILVA-PINTO, V., ARRIAZA, B., y STANDEN, V. 2010. Evaluación de la Frequencia de Espina Bífida Oculta y su Posible Relación con el Arsénico Ambiental en una Muestra Prehispánica de la Quebrada de Camarones, Norte de Chile. Revista Médica Chilena 138: 461-469.

SMITH, B.H. 1984, Patterns of Molar Wear in Hunter-Gatherers and Agriculturalists. American Journal of Physical Anthropology 63(1): 39-56.

SPERO, C.R., SIMON, G.S. y TORNETTA III, P. 1994. Clubfeet and Tarsal Coalition. Journal of Pediatric Orthopedics 14: 372-376.

STUART-MACADAM, P. 1992. Anemia in Past Human Populations. En: Diets, Demography and Disease, StuartMacadam, P. y S. Kent editores, pp. 151-170. Aldine de Gruyter, New York.

TODD, T.W. 1921. Age Changes in the Pubic Bone I: The Male White Pubis. American Journal of Physical Anthropology 3(3): 285-334.

TROTTER, M., y GLESER, G.C. 1952. Estimation of Stature from Long Bones of American Whites and Negroes. American Journal of Physical Anthropology 10 (4): 463-514.
TROTTER, M., y GLESER, G.C. 1958. A Re-Evaluation of Stature Based on Measurements Taken During Life and of Long Bones After Death. American Journal of Physical Anthropology 16 (1): 79-123.

USDA. 2010. National Nutrient Database for Standard Reference. http://www.nal.usda.gov/fnic/foodcomp/search/

VILLOTE, S., CASTEX, D., COUALLIER, V., DUTOUR, O., KNÜSEL, C.J., y HENRY-GAMBIER, D. 2010. Enthesopathies as Occupational Stress Markers: Evidence from the Upper Limb. American Journal of Physical Anthropology 142: 224-234.

WALLANDER, H.H.M., 2010. Congenital Clubfoot. Aspects on epidemiology, residual deformity and patient reported outcome. Acta Orthopaedica 81(Supl): 1-25.

WALKER, P.L. 1986. Porotic Hyperostosis in Marine-Dependent Calirrnia Indian Populations. American Journal of Physical Anthropology 69 (3): 345-354.

WALKER, P.L., BATHURST, R.R., RICHMAN, R., GJERDRUM, T. ANDRUSHKO, V.A. 2009. The Causes of Porotic Hyperostosis and Cribra Orbitalia: A Reappraisal of the Iron-Deficiency-Anemia Hypothesis. American Journal of Physical Anthropology 139 (2): 109-125.

WEISS, E. 2007. Muscle Markers Revisited: Activity Pattern Reconstruction with Controls in a Central California Amerind Population. American Journal of Physical Anthropology 133: 931-940.

WESTON, D.A. 2008. Investigating the Specificity of Periosteal Reactions in Pathology Museum Specimens. American Journal of Physical Anthropology 137: 48-59.

WHITE, T.D. y FOLKENS, P.A. 2001. Human Osteology. Academic Press, San Diego.

WILKINSON, J.A. y SEDWICK, E.M.1988. Occult Spinal Dysraphism in Established Congenital Dislocation of the Hip. Journal of Bone and Joint Surgery [Br] 70-B: 744-749.

WILLIAMS, F.M.K. y MANEK, N.J. 2007. Schmorl's Nodes: Common, Highly Heritable an Related to Lumbar Disc Disease. Arthritis and Rheumatism 57 (5): 855-860.

ZAMBITO, A., DALL'OCA, D., POLO, A., BIANCHINI, D., y ALDERGHERI, R. 2008. Spina Bifida Oculta, Foot Deformities, Enuresis and Vertebral Cleft: Clinical Picture and Neurophysiological Assessment. European Journal of Physical Rehabilitation Medicine 44 (4): 437-440.

ZHANG, N., LI, F-C., HUANG, J-H., TENG, C., y CHEN, W-S. 2010. Possible Key role of Immune System in Schmorl's Nodes. Medical Hypothesis 74: 552-554.

ZAW H., y CALDER, J.D.F. 2010. Tarsal Coalitions. Foot and Ankle Clinic 15: 349-364. 